\title{
Gamma-Carboxyglutamate in Normal and Pathological Human Middle Ear Bones
}

\author{
Gary Zajic, Malcolm D. Graham, and Jochen Schacht \\ Kresge Hearing Research Institute and Department of Otorhinolaryngology, \\ The University of Michigan, Ann Arbor, Michigan 48109, USA
}

\begin{abstract}
Summary. The presence of the amino acid $\gamma$-carboxyglutamate (GLA) was established in human middle ear bones. Proteins containing GLA have been described as being associated with normal as well as pathological calcifications. The GLA content of human incus, malleus, and stapes with $1-2 \mathrm{nmol} / \mathrm{mg}$ bone is in the range previously reported for a variety of bone. A limited number of samples with middle ear pathology, including otosclerosis, did not show altered GLA levels.
\end{abstract}

Key words: $\gamma$-Carboxyglutamate - Amino acid analysis - Middle ear ossicles - Pathology

\section{Introduction}

In 1974, a new amino acid, $\gamma$-carboxyglutamate (GLA), was discovered in bovine prothrombin and subsequently in a variety of other proteins [8, 13]. GLA is synthesized from glutamic acid residues in a post-translational, vitamin $\mathrm{K}$ - and $\mathrm{CO}_{2}$-dependent enzymatic reaction. It is of particular interest in the context of bone formation and pathology because of its presence in a unique bone protein [4] termed "bone GLA protein" [11] or osteocalcin [6]. This protein constitutes $0.5-1.0 \%$ of the total bone proteins and has a selective affinity for hydroxyapatite inhibiting crystallization, and a weak association with amorphous calcium phosphate [9]. GLA has been found in all vertebrate mineralized tissues so far investigated as well as in a variety of pathologies such as hard atheromatous plaque, renal calculi, and other ectopic calcifications. Elevated urinary excretion of GLA is also associated with active osteoporosis and conditions of dermatomyositis and scleroderma (for a review, see [1]). Available evidence, then, seems to associate the GLA-containing protein of bone with mineralization and its disorders. 
We have previously investigated calcium metabolism in the middle and inner ear in normal and pathological conditions $[7,10]$. The aim of this study was to establish the presence of GLA in middle ear bones and determine its levels in some middle ear diseases, particularly otosclerosis.

\section{Materials and Methods}

Human ossicles were donated by Dr. Jean-Bernard Causse, Béziers, France. They were obtained from surgery for middle ear diseases and stored dry until analysis. Otosclerotic stapes were examined microscopically and divided between normal superstructure and the footplate containing otosclerotic foci. All specimens were sonicated in physiological saline to remove plasma and blood, rinsed with $\mathrm{H}_{2} \mathrm{O}$, dried to constant weight, and processed according to the method of Hauschka [3]. Samples for alkaline hydrolysis were homogenized in a ground glass mortar and pestle in $2 \mathrm{~N} \mathrm{NaOH}$, since GLA is decarboxylated to glutamate under the conditions of the usual acid hydrolysis. The homogenate was transferred to alkali-resistant polypropylene tubes, placed inside glass hydrolysis tubes, frozen in ethanol/dry ice under vacuum and subsequently heated at $110^{\circ} \mathrm{C}$ for $24 \mathrm{~h}$. After centrifugation the supernatant was removed and titrated with $2 \mathrm{~N} \mathrm{HCl}$ to a $\mathrm{pH}$ of 2.20 . The volume was adjusted to $2.0 \mathrm{ml}$ with sodium citrate, $\mathrm{pH} 2.20$, and the solution passed through a $0.22-\mu \mathrm{m}$ filter before analyzing of $20-\mu 1$ aliquots.

Amino acid analysis was performed on a Dionex analyzer with a sequence of $0.2 \mathrm{~N}$ sodium citrate $\mathrm{pH} 3.25,0.2 \mathrm{~N}$ sodium citrate $\mathrm{pH} 4.25$, and $1.0 \mathrm{~N}$ sodium citrate $\mathrm{pH} 7.4$ as described by Dus et al. [2]. The column (DC5A cation exchanger) was calibrated with amino acid standard hydrolysates (Pierce Chemical, La Jolla, CA) and DL- $\gamma$-carboxyglutamate (Calbiochem-Behring, Rockford, IL). Post-column derivatization was with o-phthalaldehyde and integrations of eluted peak areas were performed on a Hewlett Packard 3390A. Since the molar concentration of GLA in the specimens was usually about $1 \%$ of that of other amino acids, most samples were chromatographed at two detector sensitivities.

All chemicals were of reagent or HPLC grade. Ultrapure $\mathrm{H}_{2} \mathrm{O}$ of $15 \mathrm{M} \Omega$ or better was used in the preparation of all solutions, the column regenerant, and the reagent.

\section{Results and Discussion}

The results establish the presence of GLA in all middle ear bones. The total bone homogenate was subjected to hydrolysis and analysis because GLA-containing proteins may also be associated with the insoluble bone matrix and resist protein extraction [12]. Several chromatographic peaks appeared close to the elution time of GLA. The identity of GLA in the specimens was established by rechromatographing an aliquot of the sample after heating in $6 \mathrm{~N} \mathrm{HCl}$, which leads to decarboxylation (Fig. 1). Some specimens were analyzed for amino acids after both acid or alkaline hydrolysis, but emphasis was placed on the latter and the quantitation of $\gamma$-carboxyglutamate (Table 1). The GLA content of incus, malleus, and stapes with $1-2 \mathrm{nmol} \mathrm{GLA} / \mathrm{mg}$ bone $(8-15 \mathrm{GLA}$ residues per 1,000 residues of glutamate) was well within the range of previously reported values for mammalian bone (Tables 1 and 2).

Footplates of otosclerotic stapes had a somewhat lower amino acid content per weight but an essentially similar relative composition (Table 1). There was no difference between otosclerotic and control specimens in the ratio of GLA to other selected amino acids. Similarly, the GLA content of middle ear structures with various other pathologies (Table 2) showed only little variability. Our 


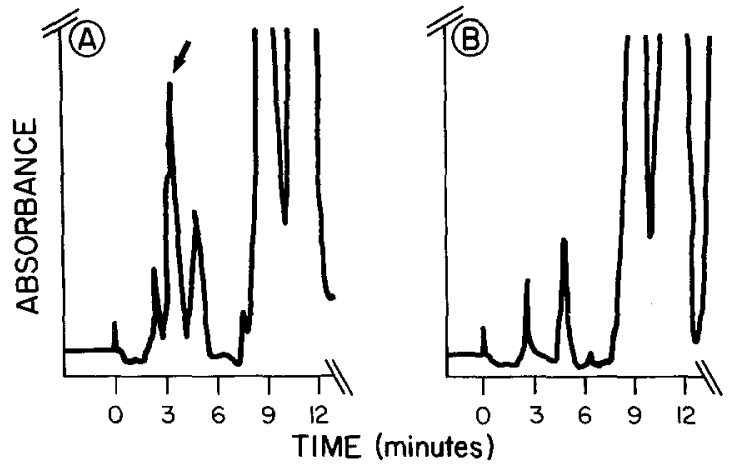

Fig. 1A, B. Partial chromatogram of bone amino acids. A The early portion of a chromatogram shows the elution of $\gamma$-carboxyglutamate (GLA) at approx. $3.5 \mathrm{~min}$ (arrow). Elution of certain amino acids or hydrolytic breakdown products near GLA has been reported previously [5, 12]. B GLA peak has disappeared after heating aliquot of sample at $\mathrm{pH} 2.2$ and $110^{\circ} \mathrm{C}$ overnight

Table 1. Concentration of selected amino acids in middle ear bones

\begin{tabular}{|c|c|c|c|}
\hline \multirow[t]{3}{*}{ Amino acid } & \multirow{3}{*}{$\begin{array}{l}\text { Incus, } \\
\text { normal }\end{array}$} & \multicolumn{2}{|l|}{ Stapes } \\
\hline & & Crux, normal & Footplate, otosclerotic \\
\hline & & \multicolumn{2}{|c|}{ nmol amino acid/mg bone (dry weight) } \\
\hline Carboxyglutamate & 0.9 & $1.9 \pm 0.3$ & $1.6 \pm 0.5$ \\
\hline Aspartate & 87 & $75 \pm 16$ & $67 \pm 15$ \\
\hline Glutamate & 112 & $131 \pm 20$ & $103 \pm 11$ \\
\hline Valine & 17 & $37 \pm 15$ & $24 \pm 7$ \\
\hline Leucine & 37 & $53 \pm 8$ & $45 \pm 10$ \\
\hline Phenylalanine & 17 & $27 \pm 4$ & $22 \pm 5$ \\
\hline
\end{tabular}

Specimens were analyzed as described in Materials and Methods. Numbers for incus are means of two specimens; numbers for stapes are means \pm SD from ten specimens

\begin{tabular}{|c|c|c|c|c|c|}
\hline \multirow[t]{2}{*}{ Structure } & \multirow[t]{2}{*}{ Middle ear pathology } & \multirow[t]{2}{*}{$n$} & GLA & GLU & \multirow{2}{*}{$\begin{array}{l}\text { GLA per } \\
1,000 \text { GLU }\end{array}$} \\
\hline & & & \multicolumn{2}{|c|}{$\mathrm{nmol} / \mathrm{mg}$ bone } & \\
\hline Incus & Normal & 2 & 0.9 & 112 & 8 \\
\hline Malleus & Normal & 1 & 1.0 & 116 & 9 \\
\hline Stapes & Normal & 10 & 1.9 & 131 & 15 \\
\hline Incus & Cholesteatoma & 1 & 1.4 & 140 & 10 \\
\hline Stapes & Otosclerosis & 10 & 1.6 & 103 & 16 \\
\hline Stapes & $\begin{array}{l}\text { Chronic serous } \\
\text { otitis media }\end{array}$ & 1 & 2.2 & 128 & 17 \\
\hline Tympanosclerotic & plaque & 1 & 9.6 & 168 & 57 \\
\hline
\end{tabular}

Specimes were analyzed after alkaline hydrolysis as described in Materials and Methods. $G L A, \gamma$-carboxyglutamate; $G L U$, glutamate 
analysis of a limited number of specimens thus does not point to GLA abnormalities in these disorders. However, a sample of tympanosclerotic plaque showed a highly elevated GLA content. While this is in agreement with reports of high GLA levels in pathological calcifications, the significance of our finding can only be assessed after suitable control material becomes available for analysis.

Acknowledgements. This work was supported by a grant from the American Otological Society. The authors wish to thank Dr. Jean Bernard Causse, Clinique d'Otologie Jean Causse, Beziers, France, for providing the otosclerotic stapes and Dr. David Lilly for his help in obtaining specimens from the Department of Otorhinolaryngology, University of Michigan.

\section{References}

1. Burnier JP, Borowski M, Furie BC, Furie B (1981) Gamma-carboxyglutamic acid. Mol Cell Biochem 39: 191-199

2. Dus K, Lindroth S, Pabst R, Smith R (1966) Continuous amino acid analysis: elution programming and automatic column selection by means of a rotating valve. Anal Biochem $14: 4152$

3. Hauschka PV (1977) Quantitative determination of carboxyglutamic acid in proteins. Anal Biochem $80: 212-223$

4. Hauschka PV, Lian JB, Gallop PM (1975) Direct identification of the calcium-binding amino acid, $\gamma$-carboxyglutamate, in mineralized bone. Proc Natl Acad Sci USA 72:3925-3929

5. Ishikawa Y, Wuthier RE (1981) Assay of $\gamma$-carboxyglutamate in tissue and body fluid by selective hydrolysis and amino acid analysis. Anal Biochem $114: 388-395$

6. Lian JB, Hauschka PV, Gallop PM (1978) Properties and biosynthesis of a vitamin K-dependent calcium binding protein in bone. Fed Proc 37:2625-2630

7. Mechigian I, Preston RE, Johnsson L-G, Schacht J (1979) Incorporation of radioactive calcium into otolithic membranes of the guinea pig after aminoglycoside treatment. Acta Otolaryngol (Stockh) 88:56-60

8. Nelsestuen GL, Zytkovicz TH, Howard JB (1974) The mode of action of Vitamin K. J Biol Chem 249:6347-6350

9. Poser JW, Price PA (1979) A method for decarboxylation of $\gamma$-carboxyglutamic acid in proteins. Properties of the decarboxylated $\gamma$-carboxyglutamic acid protein from calf bone. J Biol Chem 254: 431-436

10. Preston RE, Johnsson L-G, Hill JH, Schacht J (1975) Incorporation of radioactive calcium into otolithic membranes and middle ear ossicles of the gerbil. Acta Otolaryngol (Stockh) 80:269-275

11. Price PA, Otsuka AS, Poser JW, Kristaponis J, Raman N (1976) Characterization of a gamma-carboxyglutamic acid-containing protein from bone. Proc Natl Acad Sci USA 73: 1447-1451

12. Price PA, Lothringer JW, Nishimoto SK (1980) Absence of the vitamin K-dependent bone protein in fetal mineral. $\mathrm{J}$ Biol Chem $255: 2938-2942$

13. Stenflo J, Fernlund P, Egan W, Roepstorff P (1974) Vitamin K dependent modifications of glutamic acid residues in prothrombin. Proc Natl Acad Sci USA 71:2730-2733

Received April 24, 1984/Accepted May 11, 1984 